\title{
Theories of Collaborative Cognition: Foundations for CSCL AND CSCW TOGETHER
}

\section{GerRy Stahl}

\begin{abstract}
Both computer-supported collaborative learning (CSCL) and computer-supported cooperative work (CSCW) are centrally concerned with teamwork, learning, problem solving, knowledge building, task accomplishment and other cognitive achievements by small groups of people. There are many theories useful for framing the cognitive work that groups undertake in CSCL and CSCW settings, and they may in principle not be reducible to a single theory. However, they seem foundational for both CSCL and CSCW, including their synthesis in CSCL-at-Work. Collaboration research explores questions involving numerous distinct - though interacting - phenomena at multiple levels of description. It is important to conceptualize these group activities as involving individual participants in group processes within larger community contexts. The useful approach may be to clearly distinguish levels such as individual, small-group and community units of analysis, and to differentiate terminology for discussing these different levels. Theory in general has evolved dramatically over the ages, with a trend to extend the unit of cognition beyond the single idea or even the individual mind. Seminal theoretical works influential within collaboration research suggest a post-cognitive approach to group cognition as a complement to - if not a foundation for-analyzing cognition of individuals or of communities-of-practice. While CSCL and CSCW can both build upon shared theories of cognition, they may derive different implications from those theories as relevant for students versus professionals and may converge in cases of CSCW at Work.
\end{abstract}

\section{Theory for CSCL and CSCW}

There is no one theory of collaboration in learning and working. Research in CSCL and CSCW is guided by and contributes to a diverse collection of theories. Even the word theory means different things to different researchers and plays various distinct roles within collaborative-learning work. The reading of the history of theory presented here is itself reflective of one theoretical stance among many held, implicitly or explicitly, by collaboration researchers.

I originally tried to develop my theory of group cognition (Stahl, 2006) in response to issues of CSCL and CSCW software design. In particular, one of my research studies was an attempt to transform a basic CSCW system (BSCW) into a basic CSCL system (BCSCL or Synergia) (Ch. 7), exploring both mutual compatibilities and differences of emphasis between CSCL and CSCW. My other case studies can be categorized as either CSCL (Ch. 1, 2, 6, 12, 21) or CSCW (Ch. 
3, 4, 5) systems. These software development attempts-with their various disappointments-led to my attempts to analyze the interaction and cognition taking place (Ch. 8-13) and then-based on a recognition of the inadequacy of available methods and conceptualizations - to investigations of relevant theory ( $\mathrm{Ch}$. 14-21), using data from these studies and later from a project specifically about cognition in online teams (Stahl, 2009).

The nature and uses of theory have changed over history and continue to evolve. The theories most relevant to computer-supported collaborative learning and working - in the view developed in this chapter-concern the nature of cognition, specifically cognition in collaborating groups.

Through history, the analysis of cognition has broadened, from a focus on single concepts (e.g., Platonic ideas) or isolated responses to stimulae (behaviorism), to a concern with mental models (cognitivism) and representational artifacts (post-cognitivism). Theories that are more recent encompass cognition distributed across people and tools, situated in contexts, spanning small groups, involved in larger activities and across communities of practice. For collaborativelearning and cooperative-work research, theory must take into account interaction in online environments, knowledge building in small groups and cognition at multiple units of analysis.

\section{A brief history of theory}

Consider the role of theory in a research field like CSCL or CSCW. These fields are multi-disciplinary by their nature and as a result of their origins (see Stahl, Koschmann \& Suthers, 2006, for a history of CSCL from a perspective similar to the one here). Consider the name of CSCL, Computer-supported Collaborative Learning: it combines concerns with computer technology, collaborative social interaction and learning or education-very different sorts of scientific domains. CSCL and CSCW grew out of work in fields like informatics and artificial intelligence, cognitive science and social psychology, the learning sciences and organizational management-domains that are themselves each fundamentally multidisciplinary. Theory in these fields may take the form of predictive mathematical laws, like Shannon's (1949) mathematical theory of information or Turing's (1937) theory of computation; of models of memory and cognition; or of conceptions of group interaction and social practice. They may have very different implications for research: favoring either laboratory experiments that establish statistical regularities or engaged case studies that contribute to an understanding of situated behaviors.

In the European tradition, theory $(\theta \varepsilon \omega \rho i ́ \alpha)$ begins with the ancient Greeksespecially Socrates, Plato and Aristotle - and continues through the 2,500-yearlong discourse of philosophy. In recent times, theory has veered into unexpected directions as it has morphed into sciences based more on empirical research than on intellectual reflection. For instance, the work of Freud, Darwin and Marx replaced traditional philosophic assumptions about fixed natures of minds, organisms and societies with much more dynamic views. Theory always transcended the opinions of common sense-so-called folk theories based on the everyday experience of individuals - to synthesize broader views. But folk theories have also changed over time as they adopt popularized pieces of past philosophies; thus, a trained ear can 
hear echoes of previous theories in the assumptions of common-sense perspectives, including within current CSCL and CSCW research literature.

After the dogmatic centuries of the medieval period, philosophy took several significant turns: the rationalism of Descartes, the empiricism of Hume, the Copernican revolution of Kant, the dialectical development of Hegel, the social situating of Marx, the existential grounding of Heidegger and the linguistic turn of Wittgenstein. These all eventually led to important influences on theory in CSCL and CSCW.

In particular, for instance, the field of educational research followed this sequence of philosophic perspectives. Empiricism and positivism in philosophy of science culminated in behaviorism in biology and the human sciences. The central metaphor was that of stimulus provoking response, all objectively observable and unambiguously measurable (as critiqued in Chomsky, 1959). The major theoretical move of the generation before ours was to assert the necessity of taking into account cognitive processes in studying human behavior, from Chomsky's (1969) theories of language based on deep grammar and brain mechanisms to the mental models and internal representations modeled by artificial-intelligence programs. Human-computer interaction, the part of computer science dealing with designing for usage, has gone through a similar sequence of behaviorist and cognitivist theories (see Carroll, 2003, for numerous examples). More recently, post-cognitive theories have been influential in CSCL and CSCW, as will be discussed later.

\section{The unit of analysis}

The history of theory can be tracked in terms of the following issue: At what unit of analysis should one study thought (cognition)? For Plato $(340 \mathrm{BC} / 1941)$, in addition to the physical objects in the world, there are concepts that characterize those objects; philosophy is the analysis of such concepts, like goodness, truth, beauty or justice. Descartes (1633/1999) argued that if there is thought, then there must be a mind that thinks it, and that philosophy should analyze both the mental objects of the mind and the material objects to which they refer, as well as the epistemological relation between them. Following Descartes, rationalism focused on the logical nature of mental reasoning, while empiricism focused on the analysis of observable physical objects. Kant (1787/1999) re-centered this discussion by arguing that the mechanisms of human understanding provided the source of the apparent spatio-temporal nature of observed objects and that critical theory's task was to analyze the mind's constructivist structuring-categorization efforts. Up to this point in the history of theory, cognition was assumed to be an innate function of the individual human mind.

Hegel (1807/1967) transcended that individualist assumption. He traced the logical/historical development of mind from the most primary instinct of a living organism through stages of intentional-consciousness, self-consciousness and historical-consciousness to the most developed trans-national spirit of the times (Zeitgeist). To analyze cognition henceforth, it is necessary to follow through its biological unfolding and go beyond to the ultimate cultural understanding of a society. Figure 1 identifies Hegel's approach to theory as forming the dividing line - or watershed - between philosophies or theories oriented on the individual and those oriented to a larger unit of analysis. 


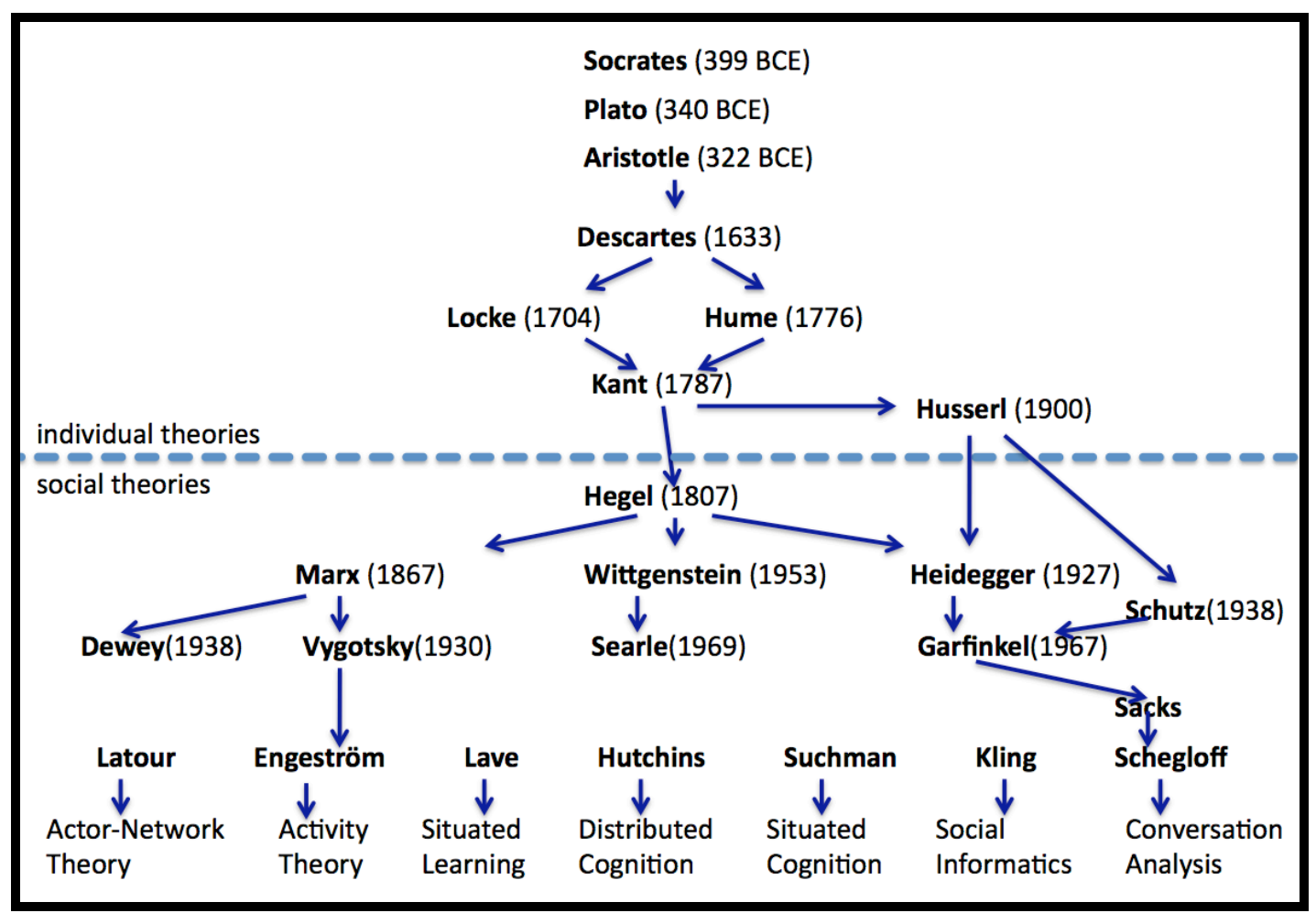

Figure 1. Adapted from (Stahl, 2006, p. 289, Fig 14-1).

Philosophy after Hegel can be viewed as forming three mainstreams of thought, following the seminal approaches of Marx (critical social theory), Heidegger (existential phenomenology) and Wittgenstein (linguistic analysis). As taken up within CSCL and CSCW, one can trace how these approaches established expanded units of analysis.

Marx (1867) applauded Hegel's recognition of the historical self-generation of mankind and analyzed this historical process in terms of the dialectical codevelopment of the social relations of production and the forces of production. His analysis took the form of historical, political and economic studies of the worldhistorical processes by which human labor produces and reproduces social institutions. Here, the study of the human mind and its understanding of its objects becomes focused at the epochal unit of analysis of social movements, class conflicts and transformations of economic systems.

Heidegger (1927/1996) radicalized the Hegelian dialectic between man and nature by starting the analysis of man from the unified experience of being-in-theworld. The Cartesian problem of a distinction between an observing mind and an objective world was thereby reversed. Heidegger, instead, had to show how the appearance of isolated minds and an external world could arise through abstraction from the primary experience of being-there, human existence inseparable from the worldly objects that one cares for and that define one's activity. The primordial unit of analysis of cognition is the involvement of people in their world.

Wittgenstein (1953) focused increasingly on language as it is used to accomplish things in the world through interpersonal communication. He rejected his own early view (Wittgenstein, 1921/1974), which reduced a rationalist conception of propositional, logical language to a self-contradictory position. Now, linguistic meaning no longer dwelt in the heads of users or the definitions of the words, but in communicational usage. Echoing the lived world of phenomenology, 
Wittgenstein acknowledged the role of the human form-of-life. He also conceptualized language as the playing of language games, socially established forms of interaction. The unit of analysis shifted from mental meanings to interpersonal communications in the context of getting something done together.

Marx, Heidegger and Wittgenstein initiated the main forms of post-Kantian, post-Hegelian philosophy and scientific theory (Stahl, 2010c). Kant represents the culmination of the philosophy of mind, in which the human mind is seen as the active constructor of reality out of its confrontation with the objects of nature, which are unknowable except through this imposition of human structuring categories. With Kant - over two hundred years ago - the human mind is still a fixed unit consisting of innate abilities of the individual person, despite how much his philosophy differs from naïve realist folk theories, which accept the world as fundamentally identical with its appearance to the human observer. Hegel overthrows the Kantian view of a fixed nature of mind by showing how the mind has itself been constructed through long sequences of processes. The Hegelian construction of mind can be understood in multiple senses: as the biological development of the brain's abilities as it grows from newborn to mature adult; as the logical development from simple contrast of being and non-being to the proliferation of all the distinctions of the most sophisticated understanding; or as the historical development from primitive homo sapiens to modern, civilized, technological and cultured person. After Hegel, theory shifted from philosophy to science, to explore the biological, logical and historical processes in more detail and to verify them empirically. Followers of Marx, Heidegger and Wittgenstein adopted approaches to this that can be characterized as social, situated and linguistic. They are all constructivist, following Kant's insight that the structure of known objects is constructed by the knowing mind. However, they all focus on a unit of analysis broader than the isolated individual mind of Descartes.

\section{Seminal theories for CSCL and CSCW}

The social, situated and linguistic theories of Marx, Heidegger and Wittgenstein entered the discourse of CSCL and CSCW literature with researchers coming from the various scientific traditions that went into forming these research domains, including psychology, education, social science, design studies, computer science and artificial intelligence (e.g., Dourish, 2001; Ehn, 1988; Floyd, 1992; Schön, 1983). Although these fields each introduced various theoretical perspectives, we can see the major philosophic influences largely through several seminal texts: Mind in Society (Vygotsky, 1930/1978), Situated Learning (Lave \& Wenger, 1991), Lectures on Conversation (Sacks, 1962/1995) and Understanding Computers and Cognition (Winograd \& Flores, 1986).

Mind in Society is an edited compilation of Vygotsky's writings from the early 1930s in post-revolutionary Russia, which has been influential in the West since it appeared in English in 1978. Critiquing the prevailing psychology as practiced by behaviorists, Gestalt psychologists and Piaget, Vygotsky did not try to fit psychology superficially into the dogmatic principles of Soviet Marxism, but rather radically rethought the nature of human psychological capabilities from the developmental approach proposed by Hegel and Marx. He showed how human perception, attention, memory, thought, play and learning (the so-called mental 
faculties) were products of developmental processes - in terms of both maturation of individuals and the social history of cultures. He proposed a dynamic vision of the human mind in society, as opposed to a fixed and isolated function. The Hegelian term, mediation, was central for Vygotsky, as it is for CSCL and CSCW. Even in his early years still talking about stimulus and response, he asked how one stimulus could mediate the memory of, attention toward or word retrieval about another stimulus (p. iii). In Hegelian terms, this is a matter of mediating (with the first stimulus) the relation (memory, attention, retrieval) of a subject to an object (the second stimulus). This is fundamental to CSCL and CSCW because there the learning of students or the work of professionals is mediated by technological networking as well as by collaborative interaction. Another popular term from Vygotsky is the zone of proximal development (pp. 84-91). This is the learning distinction and developmental gap between what individuals can do by themselves (e.g., on pre- and post-tests) and what they can do in collaboration (e.g., situated in a small group). A group of children may be able to achieve cognitive results together that they will not be able to achieve as individuals for a couple more years. This is consistent with Vygotsky's principle that people develop cognitive abilities first in a social context-supported or mediated by peers, mentors or cognitive aids like representational artifacts - and only later are able to exercise these cognitive abilities as individuals. Vygotsky's theory, if carried beyond where he had time to develop it, implies that collaborative learning - including in workplaces-provides the foundation upon which all learning is built. Methodologically, it argues against judging the outcomes of collaborative learning by evaluating or assessing individuals outside of their collaborative settings.

Situated Learning went beyond Vygotsky in expanding the unit of analysis for learning at work. For Vygotsky and his followers, analysis must include the mediating artifact (tool or word) and the mentor or group. For Lave and Wenger, the unit of analysis is the even larger community-of-practice. Adopting the theoretical and analytical centrality of social practices in Marx, they focused on learning-at-work as the development of processes and relationships within the communities in which individuals participated. Learning-at-work was viewed on the model of apprenticeship, in which an individual gradually - and primarily tacitly - adopts the practices that are established within the community in which the individual is becoming a member. Within CSCL, this approach can be seen in the idea that one learns mathematics by adopting the (predominantly discursive) practices of mathematicians, such as using mathematical symbolisms, making conjectures about mathematical objects and articulating deductive arguments (Sfard, 2008). The CSILE project (Scardamalia \& Bereiter, 1996), a pioneering CSCL effort, tried to support the communicative practices seen in professional research communities within the learning communities of school classrooms; the unit of analysis for knowledge building mediated by the CSILE discussion software was the discourse of the classroom as a whole. This illustrates a kind of CSCL-atWork in reverse, where learning incorporates work practices.

Lectures on Conversation laid the cornerstone of Conversation Analysis (CA), which studies the linguistic practices of communities. It was based on the ethnomethodological (Garfinkel, 1967) perspective, grounded in both Wittgenstein's linguistic analysis and Heidegger's (1927/1996) and Husserl's (1936/1989) phenomenological approach. Like Wittgenstein, CA analyzed language at a unit larger than the isolated word or speech act. CA often focuses on adjacency pairs used in conversation-see (Schegloff, 2007) for a systematic 
presentation based on 40 years of research by the CA community on adjacency-pair structure. An adjacency pair is a sequence of two or three utterances that elicit or respond to each other, such as a question and answer. The significance of the adjacency pair as a unit of analysis is that it includes contributions by multiple people involved in an interaction, and thereby avoids treating speech as an expression of an individual mind. This is analogous to Marx' (1867) focus on the act of commodity exchange between people as a unit of interaction in contrast to theories that dwell on rational decisions of an individual (Stahl, 2010c). What is important in CA is the mode of interaction carried out by the adjacency pair situated in its on-going, sequential discourse context. This should be contrasted with approaches that code isolated utterances based on assumptions about mental models inside the individual mind of the speaker. A CA analysis explicates how a dyad or small group builds upon and solicits each other's contributions, thus providing insight into patterns of collaboration. In a sense, the CA unit of analysis is not simply the adjacency pair, which includes multiple speakers, but the linguistic community, which establishes the member methods underlying adjacency-pair practices.

Understanding Computers and Cognition presents a Heideggerian critique of the rationalist foundations of artificial intelligence by a leading AI researcher. The book reviews three theories that endorse contextual analysis: Heidegger's (1927/1996) situated being-in-the-world, Gadamer's (1960/1988) historically

grounded conception of interpretation and Maturana's (1987) ecological version of cognition. These theories emphasize the inseparability of the mind from its larger context: human being engaged in the world, interpretation oriented within the horizon of history and the organism bound in a structural coupling with its environment. In contrast, AI software represents mental functions as isolatable units of rational computation, which in principle cannot capture the richness and complexity of situated human cognition and collaboration. The larger, primarily tacit (Polanyi, 1966) unit of context cannot be adequately represented in a computer system (Stahl, 2010d). Accordingly, the role of computer software should be to support human interaction and collaboration, rather than to replace or fully model human cognition.

The writings of Vygotsky, Lave \& Wenger and Sacks further develop the perspectives of Marx, Heidegger and Wittgenstein that view cognition as social, situated and linguistic. Winograd-like other CSCW researchers, including Ehn and Dourish-reviews the foundational post-cognitive theories and considers the implications for computer-supported collaboration. But these theories can be-and have been-taken in different directions by researchers when it comes time to follow their implications for research conceptualizations and methods. These directions can perhaps best be seen in terms of alternative theories of individual, small-group and community cognition in collaboration research.

\section{Theories of individual cognition}

Many research questions within CSCL and CSCW involve individual cognition. Collaboration research is often treated as a sub-discipline of educational or socialpsychological research, oriented to the mind of the individual student or worker, within group contexts. Such research can follow traditional scientific research 
paradigms based on pre-Kantian empiricism (Hume) and/or rationalism (Locke). This research often adopts a constructivist approach, based on the Kantian principle that the student or worker constructs his or her own understanding of reality. Such constructivist theory is cognitivist, in that it involves assumptions about cognitive processes in the mind of the individual underlying the individual's observed behaviors. For instance, a student's responses in a test situation are assumed to be reflective of the student's mental models of some knowledge content, as construed by the student.

Work within CSCL or CSCW certainly acknowledges the importance of the larger social, historical and cultural context. However, it often treats this context as a set of environmental variables that may influence the outcomes of individual student or worker cognition, but are analytically separable from that cognition. In this way, cognition is still treated as a function of an individual mind. This approach may be called socio-cognitive. It acknowledges social influences, but tries to isolate the individual mind as a cognitive unit of analysis by controlling for these external influences.

Followers of Vygotsky, by contrast, are considered socio-cultural. They recognize that cognition is mediated by cultural factors. Yet, they still generally focus on the individual as the unit of analysis. They investigate how individual cognition is affected by cultural mediations, such as representational artifacts or even by collaborative interactions. Vygotsky himself-who was after all a psychologist - generally discussed the individual subject. For instance, his concept of the zone of proximal development measured an individual's ability when working in a group, not the group's ability as such. Vygotsky was trying to demonstrate that individual cognition was derivative of social or intersubjective experiences of the individual, and so his focus was on the individual rather than explicitly on the social or intersubjective processes in which the individual was involved.

In this sense, much cognitive research investigates individual cognition in settings of collaboration. In fact, if the research is based on testing of the individual before and after a collaborative interaction and does not actually analyze the intervening interaction itself, then it is purely an analysis at the individual unit of analysis, where the collaboration is merely an external intervention measured by presumably independent variables.

If one looks closely at most studies that claim to be about small-group collaboration, one finds that they adopt this kind of methodical focus on the individual within a group setting and treat the group interaction as an external influence on the individual. This is particularly clear in the writings of cooperative learning that preceded CSCL (e.g., Johnson \& Johnson, 1989). As defined within CSCL (Dillenbourg, 1999), in "cooperative" learning students divide up group work and then put the individual contributions together, whereas in "collaborative" learning students do the work together. Similarly on the methodological level, in cooperative learning the analyst distinguishes the contributions to the work and focuses on the learning by the individuals as a result of the cooperative experience, whereas in collaborative learning the analyst may chose to focus on the group processes. The same is true for small-group studies of sociology and social psychology in CSCW: they usually treat the group as a context and analyze the effects on the individual, rather than analyzing the group phenomena and treating the individuals as contributors to the group processes. 
A final example of a theory of individual cognition is psycho-linguistic contribution theory (Clark \& Brennan, 1991). This particular paper is often cited in CSCL and CSCW literature. Although the paper claims to be in the Conversation Analysis tradition, it translates the adjacency-pair structure of grounding shared understanding into the contributions of the individuals. It analyzes the individual contributions as expressions of their mental representations or personal beliefs and treats the resultant shared understanding as a matter of similar mental contents or acceptance of pre-conceived beliefs rather than as a negotiated group product of collaboratively co-constructed meaning making. In a later paper, Clark (1996) tries to unite cognitivism with Conversation Analysis, but he analyzes the situated, engaged interaction as an exchange of signals between rationally calculating minds, who identify deliberate actions based on "knowledge, beliefs and suppositions they believe they share" (p. 12). Interestingly, Clark (1996) concludes in favor of recognizing two independent theories with different units of analysis (the individual or the community, but ironically not the small group): "The study of language use must be both a cognitive and a social science," he says (p.25).

\section{Theories of community cognition}

In striking contrast to the insistent focus on the individual as the unit of analysis is the social-science perspective on social processes. Marx provides a good example of this. Where economists of his day analyzed economic phenomena in terms of rational choices of individual producers and consumers, Marx critiqued the ideology of individualism and in its place analyzed sweeping societal transformations such as urbanization, the formation of the proletariat, the rise of the factory system, and the drive of technological innovation. Lave and Wenger (1991) brought this approach to educational theory, showing for instance how an apprenticeship training system reproduces itself as novices are transformed into experts, mentors and masters. Learning is seen as situated or embedded in this process of the production-and-reproduction of structures of socially defined knowledge and power. For Lave and Wenger, the community or community-ofpractice is the structure within social organizations (corporations, cultural institutions, etc.) where interaction, task accomplishment, professional exchanges, training and institutional learning take place; it is a prime location for CSCL-atWork.

The theoretical importance of the situation in which learning and work take place is widely acknowledged in CSCL and CSCW. Suchman (1987) demonstrated its centrality for human-computer interaction from an anthropological perspective heavily influenced by both Heidegger (via Dreyfus, (1991) and Garfinkel (1967), leading to conclusions similar to Winograd's (Winograd \& Flores, 1986). Suchman (1987) and Nardi (1996) have helped to establish ethnographic methods - oriented to community phenomena-as relevant to CSCL and CSCW research. Unfortunately, even perspectives like situated cognition can take a reductive turn: Recent commentaries on situated cognition (Robbins \& Aydede, 2009) and distributed cognition (Adams \& Aizawa, 2008) frame the issues at the individual level, to the extreme of reducing all cognitive phenomena to neural functions.

Building on Vygotsky and his Russian colleagues, Activity Theory (Engeström, 1987; Engeström, 1999; Kaptelinin \& Nardi, 2006) insists on taking 
an entire activity system as the unit of analysis. In his triangular analysis rubric, Engeström extends Vygotsky's mediation triple of subject, mediator and object to include mediating dimensions from Marx's theory: the division of labor, the rules of social relations and the community of productive forces. Like discourse analysis (Gee, 1992), activity theory is repeatedly looking at small-group interactions but only seeing the larger, societal issues. For instance, when activity theory addresses the study of teams in the most detail in Chapter 6 of (Engeström, 2008), it is mostly concerned with the group's situation in the larger industrial and historic context; rather than with analyzing how the group interactionally builds knowledge, it paraphrases how the group deals politically with organizational management issues.

There is something of this avoidance of the small group as the scientific focus in other theories popular in CSCL and CSCW as well, for instance even in distributed cognition. In seminal statements of post-cognitivist theory, Hutchins has indeed explicitly pointed to group-cognitive phenomena:

- "Cognitive processes may be distributed across the members of a social group" (Hollan, Hutchins \& Kirsh, 2000, p. 176).

- "The cognitive properties of groups are produced by interaction between structures internal to individuals and structures external to individuals" (Hutchins, 1996, p. 262).

- "The group performing the cognitive task may have cognitive properties that differ from the cognitive properties of any individual" (Hutchins, 1996, p. 176).

However, rather than focusing on these group phenomena in detail, he prefers to analyze socio-technical systems and the cognitive role of highly developed artifacts (e.g., airplane cockpits or ship navigation tools). Certainly, these artifacts have encapsulated past cultural knowledge (community cognition), and Hutchins' discussions of this are insightful. But in focusing on what is really the community level-characteristically for a cultural anthropologist-he does not generally analyze the cognitive meaning making of the group itself (but see his analysis of group or organizational learning in Chapter 8 of Hutchins, 1996, for an exception and an exemplary analysis of CSCL-at-Work).

Even ethnomethodology (Garfinkel, 1967; 2006) and conversation analysis (Sacks, 1962/1995; Sacks, Schegloff \& Jefferson, 1974; Schegloff, 2007) consider themselves social sciences, versions of sociology or communication studies, but not sciences of the small-group unit of analysis. They aim to analyze social practices, defined across a whole society or linguistic community. This may be a quibble over words, for they do in fact define many important processes at the group unit, although they call them social.

Vygotsky, too, used the term social in an ambiguous way when he said that learning takes place socially first and then later individually. Socially can refer to two people talking as well as to transformations of whole societies. But for the sake of distinguishing levels of description or units of analysis in CSCL and CSCW, it seems important to make clear distinctions. Table 1 suggests sets of different terms for referring to phenomena at the individual, small-group and societal levels. The distinction of these three levels has previously been argued for by (Rogoff, 1995), (Dillenbourg et al., 1996), (Stahl, 2006) and others. We start with these three levels, which seem particularly central to much CSCL and CSCW work, although other levels might also usefully be distinguished, such as "collective intelligence" at the 
classroom/shop-floor level or "collective practices" at the school/company level (Guribye, 2005; Jones, Dirckinck-Holmfeld \& Lindström, 2006; Looi et al., 2011). Perhaps consistent usage of such terminological distinctions would lend clarity to the discussion of theories in CSCL and CSCW.

Table 1. Terminology for phenomena at the individual, small-group and community levels of description. From (Stahl, 2010a, p. 27, Table 2.1).

\begin{tabular}{|c|c|c|c|}
\hline Level of description & Individual & Small group & Community \\
\hline Role & Person / student & Group participant & Community member \\
\hline Adjective & Personal & Collaborative & Social \\
\hline Object of analysis & Mind & Discourse & Culture \\
\hline Unit of analysis & $\begin{array}{l}\text { Mental } \\
\text { representation }\end{array}$ & Utterance response pair & $\begin{array}{l}\text { Socio-technical activity } \\
\text { system, mediating } \\
\text { artifacts }\end{array}$ \\
\hline Form of knowledge & Subjective & Intersubjective & Cultural \\
\hline Form of meaning & Interpretation & $\begin{array}{l}\text { Shared understanding, } \\
\text { joint meaning making, } \\
\text { common ground }\end{array}$ & $\begin{array}{l}\text { Domain vocabulary, } \\
\text { artifacts, institutions, } \\
\text { norms, rules }\end{array}$ \\
\hline Learning activity & Learn & Build knowledge & Science \\
\hline $\begin{array}{l}\text { Ways to accomplish } \\
\text { cognitive tasks }\end{array}$ & Skill, behavior & $\begin{array}{l}\text { Discourse, group methods, } \\
\text { long sequences }\end{array}$ & $\begin{array}{l}\text { Member methods, } \\
\text { social practices }\end{array}$ \\
\hline Communication & Thought & Interaction & Membership \\
\hline Mode of construction & Constructed & Co-constructed & Socially constructed \\
\hline $\begin{array}{l}\text { Context of cognitive } \\
\text { task }\end{array}$ & Personal problem & Joint problem space & Problem domain \\
\hline Context of activity & Environment & Shared space & Society \\
\hline Mode of Presence & Embodiment & Co-presence & Contemporary \\
\hline Referential system & Associations & Indexical field & Cultural world \\
\hline $\begin{array}{l}\text { Form of existence } \\
\text { (Heidegger) }\end{array}$ & $\begin{array}{l}\text { Being-there } \\
\text { (Dasein) }\end{array}$ & $\begin{array}{l}\text { Being-with (Mitsein), } \\
\text { Being-there-together at } \\
\text { the shared object }\end{array}$ & $\begin{array}{l}\text { Participation in } \\
\text { communities of } \\
\text { practice (Volk) }\end{array}$ \\
\hline Temporal structure & $\begin{array}{l}\text { Subjective } \\
\text { experiential } \\
\text { internal time }\end{array}$ & $\begin{array}{l}\text { Co-constructed shared } \\
\text { temporality }\end{array}$ & $\begin{array}{l}\text { Measurable objective } \\
\text { time }\end{array}$ \\
\hline Theory of cognition & Constructivist & Post-cognitive & Socio-cultural \\
\hline Science & $\begin{array}{l}\text { Cognitive and } \\
\text { educational } \\
\text { psychology }\end{array}$ & Group cognition theory & $\begin{array}{l}\text { Sociology, } \\
\text { anthropology, } \\
\text { linguistics }\end{array}$ \\
\hline Tacit knowledge & $\begin{array}{l}\text { Background } \\
\text { knowledge }\end{array}$ & Common ground & Culture \\
\hline Thought & Cognition & Group cognition & Practices \\
\hline Action & Action & Inter-Action & Social praxis \\
\hline
\end{tabular}

\section{Theories of small-group cognition}

As suggested above, the CSCL and CSCW-related literature on small groups and on post-cognitive phenomena provide some nice studies of the pivotal role of small groups, but they rarely account for this level of description theoretically. They are almost always in the final analysis based on either a psychological view of mental 
processes at the individual level or a sociological view of rules at the community level. They lack a foundational conception of small groups as a distinct level of analysis and description. They often confuse analysis at the small-group level and at the societal level, and they lack a developed account of the relationships among the individual, small group and community of practice. Yet there are distinct phenomena and processes at each of these levels, and analyses at different levels of description reveal different insights.

It seems obvious that the small-group level should be considered particularly central to CSCL and CSCW theory, because these fields are explicitly concerned with supporting collaboration, knowledge co-construction or group cognition. There are few other domains in which such activities by small groups are in principle such a central concern. We have seen resistance to this focus on the small group, for instance, in the case of activity theory - which could profitably be used to investigate group processes - where Engeström (2008) argued against a focus on small groups because workplace teams tend to come and go quickly, forming changing knots of co-workers around ephemeral tasks.

Engeström's argument echoes the attitude of Schmidt \& Bannon (1992) in their programmatic opening article of the inaugural issue of the CSCW journal. In rejecting the use of the term "group" as a defining concept for CSCW, they reduced the theoretical perspective to one focused on individuals "articulating" (i.e., coordinating) their "distributed individual activities" (p. 15). They made this move despite claiming that their concept of "cooperative work" was congruent with Marx' (1867) definition of cooperative work as "multiple individuals working together in a conscious way in the same production process." In 1867, Marx was analyzing in detail the historic shift of the unit of production from the individual to the group, but in 1992 Schmidt \& Bannon insist on still focusing on the individual. They complain that the units of cooperative workers are not well-formed, clearly defined, persisting groups. But that is beside the point.

The theoretical point is that interacting people accomplish work tasks and associated cognitive tasks (including articulation tasks and power struggles) through group interaction processes, and that these should be analyzed as such, as local achievements of group interaction, not simply as sums of individual actions and reactions or as effects of external societal forces. In particular, as cooperative work shifts from the manual factory production of Marx's time to knowledge building and other forms of intellectual production in the information age, groupcognition phenomena call more strongly for analysis at the small-group unit. A small group is not defined ontologically as a certain number of human bodies adjacent to each other for a certain period of clock time, but as a cognitive unit capable of achieving specific tasks of cooperative work and collaborative knowledge building through the interaction among individuals within a larger community context.

There are distinct phenomena and processes at the individual, small-group and community-of-practice levels, and analyses at these different levels of description can reveal different insights. As Grudin (1994) put it in terms of the needs of CSCW,

Computer support has focused on organizations and individuals. Groups are different. Repeated, expensive groupware failures result from not meeting the challenges in design and evaluation that arise from these differences. (p. 93) 
There are theoretical, methodological and practical reasons for both CSCL and CSCW to focus on the small-group unit of analysis.

If group phenomena are treated seriously as first-class objects of theory, then one can study how small groups engage in cognitive activities such as: interpersonal trains of thought, shared understandings of diagrams, joint problem conceptualizations, common references, coordination of problem-solving efforts, planning, deducing, designing, describing, problem solving, explaining, defining, generalizing, representing, remembering and reflecting as a group. In CSCL and $\mathrm{CSCW}$ studies of text chat or discussion forums, for instance, analysis can show group-cognitive accomplishments emerging from the network of meaningful references built up by postings, demonstrating how the group's self-formation and its cognitive accomplishments are enacted in situated interaction. An analytic focus on the group unit of analysis need not imply that groups exist as ontological entities whenever people are observed in proximity or in communication with one another. The small group is a theoretical construct, not a simple physical observable. Of course, effective groups have to constitute themselves as such and they can change dramatically over time. It is not the more-or-less persistent physical group that is important, but the group processes, which may extend over seconds, days or years. A single momentary exchange of greetings may be a group process of interest, as shown by the early conversation analyses of telephone answering on a help phone line (Hopper, 1992).

A theoretical approach that focuses on small-group interaction is that of dialogicality (Linell, 2001; 2009; Mercer, 2000; Wegerif, 2007). Dialogical theory goes back to Bakhtin (1986), a contemporary of Vygotsky. It stresses the linguistic nature of interaction. It also reiterates the idea that a person's identity as an individual arises through the confrontation with one's partners in dialogue - a view that goes back beyond Mead (1934/1962) to Hegel's (1807/1967) master-slave dialectic (Stahl, 2006, p. 333f). The notion of dialogue partners coming from different perspectives and negotiating from these is an important contribution of dialogic inquiry (Wells, 1999). Another key concept is that of a shared dynamic dialogic space, within which knowledge building can take place (Kershner et al., 2010). This is similar to the joint problem space of (Teasley \& Roschelle, 1993), but now developed in an unambiguously post-cognitive manner.

The idea of an interactional space for interaction within a small group is central to group-cognition theory (Stahl, 2006) as well. The term group cognition was coined to stress the goal of developing a post-cognitive view of cognition as the possible achievement of a small group collaborating so tightly that the process of building knowledge in the group discourse cannot be attributed to any individual or even reduced to a sequence of contributions from individual minds. For instance, the knowledge might emerge through the interaction of linguistic elements, situated within a sequentially unfolding set of constraints defined by the group task, the membership of the group, and other local or cultural influences, as well as due to the mediation of representational artifacts and media used by the group - within a larger horizon of language and history (Gadamer, 1960; Husserl, 1936).

The theory of group cognition absorbs many ideas from the theories discussed above, including that of a shared dynamic dialogical space. Despite some scattered case studies by the authors already mentioned and their colleagues, there is yet not much documentation and analysis of empirical instances of effective group cognition. The analysis of group cognition needs not only specially focused 
methods to track its occurrence, but even prior to that it needs appropriate collaboration technologies, group methods, pedagogy and guidance to structure and support groups to effectively build knowledge that can be shown to be a group product not reducible to individual mental representations. The Virtual Math Teams Project was launched to generate a data corpus that would allow for the analysis of group cognition. This project and some analyses by a number of researchers are documented in (Stahl, 2009). Group-cognition theory focuses on the sequential team interaction within case studies of small-group collaboration. This takes place within an interaction space or a world in the Heideggerian (1927) sense, which opens up to allow the production of group-cognitive accomplishments. The interaction that takes place within such a world - whether face-to-face or online - is subject to a variety of constraints, as pictured in Figure 2.

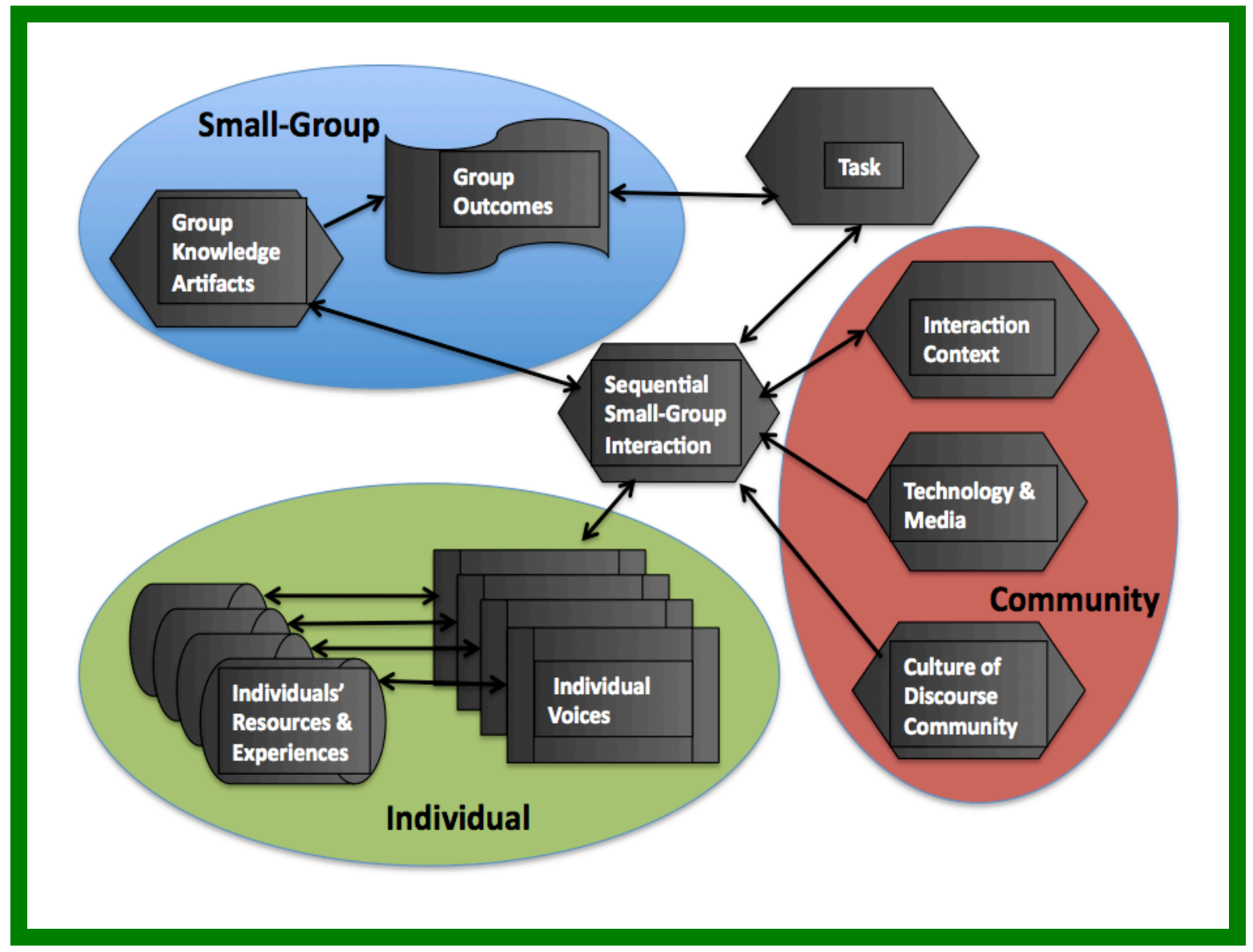

Figure 2. A diagram of constraints on sequential small-group interaction. From (Stahl, 2010b, p. 256, Figure 1).

Note that Figure 2 is not intended to be a model of objects and processes. Rather it tries to present some of the complex constraints on the discourse through which group cognition might be achieved. Neither the physical individuals nor their group are represented here as such; the dialogical voices (Bakhtin, 1986) of the individuals enter into the sequential team interaction and respond to it. Over time, the sequential team interaction forms the central shared dynamic dialogic space within which the group-cognitive constraints interact. Behind the individual voices that enter into this interaction space are not so much minds containing mental representations, as a fluid background of past experiences and developed resources for action, which surface based on relevance to the interaction. The team discourse 
is situated in the shared dialogical context generated by the on-going interaction itself; the culture and history associated with the group's community-of-practice; and the socio-technical environment including the media of communication. The interaction is goal-oriented toward the task - as given externally but as enacted by the group - and mediated by a variety of kinds of artifacts, including codifications of knowledge products previously generated by the group. These artifacts might end up among the team outcomes, in relation to the guiding task. Of course, other constraints and influences are possible as well, coming for instance from the guidance of a teacher or the motivations of a reward system. The point is that one can picture the whole system producing cognitive accomplishments without having to postulate mental representations in individual minds, let alone to reduce the whole system either to rational mental decisions or to regulation by rules of social institutions.

The term constraint in Figure 2 is chosen to be a neutral term, not implicating a notion of mechanistic causality. While it is clear that the traditional conception of causality is inadequate - stemming back to Aristotle and metaphors of physical mechanics from the everyday world - it is less obvious how to think about the working of the constraints upon group cognition. Folk theory adopts a mechanistic worldview, or even an anthropomorphic view of nature combined with a mechanistic view of causality. Observable behavior of people is taken to be the result of rational decision making in the heads of individuals causing the people to behave as a result of the minds acting as the agency for causing words to be produced and limbs to be moved. But the linguistic turn of Wittgenstein (Wittgenstein, 1953) and even more so the recent practice turn (Schatzki, Knorr Cetina \& Savigny, 2001) have veered radically away from such a view.

Latour (1992) seems to be working toward a post-cognitive notion of causality, perhaps relying heavily on Hegel's notion of mediation. Interestingly, he not only argues against the hegemony of individual minds as agents in the social world, but he also argues against the adequacy of our notion of the social (Latour, 2007). History is made neither by rational decisions of individual minds nor by the workings of society. Rather, it is the result of a complex network of mediating actors, including all kinds of artifacts as well as human actors. Thus, Latour seems to be advocating an analytic approach that steers clear of both individual minds and social institutions to focus on a middle ground. He selects the term 'group' for this middle ground, precisely because it can be used without implying theoretical preconceptions: "The word 'group' is so empty that it sets neither the size nor the content.... This is exactly why I have chosen it" (Latour, 2007, p. 29). Figure 2 may illustrate the kind of network that he would endorse for picking apart and then reassembling instances of group cognition.

Such new conceptualizations of cognition, agency and causality may be particularly appropriate for collaborative learning and cooperative work, especially as they are brought together in CSCL-at-Work. Here, the focus is on interpersonal communication and work practices of groups. CSCL-at-Work should adopt these new perspectives for facilitating computer-mediated discourse focused on improving small-group practices. 


\section{A multiplicity of theories of cognition}

In general, CSCL, CSCW and CSCL-at-Work raise many fundamental questions for traditional theories, oriented as they are to small groups and to online interaction. The accustomed characteristics of the physical world, in which colleagues and interlocutors are embodied and visible to each other, are often missing in these virtual settings, and that brings into question numerous assumptions of folk theories and traditional approaches. The group itself has no identity as a physical body and has no brain to possess its knowledge; it relies on external memories, which differ essentially from personal memories (Donald, 1991). The online world - shared dialogical space - has no location or extension. Group members can come from around the world and do not necessarily share local connections and culture. CSCL and CSCW involve students and workers in qualitatively different social relations of production, modes of being in the world or forms of life; even Marx, Heidegger and Wittgenstein's foundational philosophies of post-cognitive theory need to be rethought for virtual groups. Concepts of causality, world, knowledge, cognition, intersubjectivity, interaction and presence need to be reconceptualized for theories of collaboration.

There are many avenues for developing theories of CSCL-at-Work, as reviewed in this chapter. Although there are some similarities among these alternatives — often in terms of their critiques of earlier theories - there are strong differences of position and perspective. This is not necessarily a problem. There is a huge assortment of processes taking place in successful collaborative events: at multiple time scales and involving different aspects of interaction. It is possible to raise innumerable research questions, each requiring possibly different methods of investigation at various levels of analysis. It is likely that CSCL-at-Work requires multiple theories, which are not reducible to one grand unifying theory and that even seem incommensurate with each other. This goes essentially beyond the common notion of mixed methods, in which two or more methods of analysis are used to triangulate a single phenomenon from different angles. There are distinct phenomena at different levels of description - and they interact with each other in complex ways in group settings.

CSCL and CSCW study collaboration, from a design perspective. CSCL often involves whole classrooms or schools and widespread educational practices; CSCW often involves large departments or factories and widespread work practices. At the opposite end of the spectrum, much of the actual work comes down to tasks done by individuals. But much of the coordination, decision making, articulation, brainstorming, discovery and knowledge building is accomplished by small groups. Community accomplishments are thereby mediated by small groups, which carry out the necessary activities and involve the individuals. Collaboration involves a tight and complex integration of processes at the individual, small-group and community levels. Computer support for collaboration must provide supports at each level while also supporting the integration of the activities at all levels. To provide insight for this, CSCL and CSCW research must recognize the levels as distinct and conduct analyses at all levels.

Some time ago when I was a CSCL researcher working in a CSCW research lab, I argued that CSCL and CSCW were closely related in terms of their theoretical foundations, but that they differed in terms of the population on which they focused (Stahl, 2002). CSCL is concerned with students who are learning 
practices at which they are still novices. In the Vygotskian metaphor, they are experiencing group-cognitive processes that they can subsequently internalize. $\mathrm{CSCW}$ is concerned with professionals who are refining their skills as experts. They may be engaged in group-cognitive processes which cannot be internalized by an individual, such as navigating a large naval vessel (Hutchins, 1996). The theme of this book, learning at work, demonstrates that even at the level of concrete learning activities the two often separated research fields have much in common.

In CSCL-at-Work, there are many phenomena of interest, and they are largely defined by the theories that conceptualize them. So different theories can be talking about quite different phenomena (although they may unfortunately be calling them by the same name). In order to avoid confusion and arguments about pseudoproblems, we need to be clear about the theories behind research questions, assumptions, methodologies, analysis tools, findings and claims in this research.

This chapter has sketched some of the theoretical landscape underlying CSCL and CSCW research. Progress in further developing theories of CSCL-at-Work will require careful analysis of case studies - such as those in this volume - and experimental results guided by theoretical perspectives that are clearly enunciated.

\section{References}

Adams, F., \& Aizawa, K. (2008). The bounds of cognition. Malden, MA: Blackwell.

Bakhtin, M. (1986). Speech genres and other late essays (V. McGee, Trans.). Austin, TX: University of Texas Press.

Carroll, J. (Ed.). (2003). HCI models, theories and frameworks: Toward a multidisciplinary science. San Francisco, CA: Morgan Kaufmann Publishers.

Chomsky, N. (1959). Review of verbal behavior, by B. F. Skinner. Language. 35(1), 26-57.

Chomsky, N. (1969). Aspects of a theory of syntax. Cambridge, MA: MIT Press.

Clark, H. (1996). Using language. Cambridge, UK: Cambridge University Press.

Clark, H., \& Brennan, S. (1991). Grounding in communication. In L. Resnick, J. Levine \& S. Teasley (Eds.), Perspectives on socially-shared cognition. (pp. 127-149). Washington, DC: APA.

Descartes, R. (1633/1999). Discourse on method and meditations on first philosophy. New York, NY: Hackett.

Dillenbourg, P. (1999). What do you mean by "collaborative learning"? In P. Dillenbourg (Ed.), Collaborative learning: Cognitive and computational approaches. (pp. 1-16). Amsterdam, NL: Pergamon, Elsevier Science.

Dillenbourg, P., Baker, M., Blaye, A., \& O'Malley, C. (1996). The evolution of research on collaborative learning. In P. Reimann \& H. Spada (Eds.), Learning in humans and machines: Towards an interdisciplinary learning science. (pp. 189-211). Oxford, UK: Elsevier.

Donald, M. (1991). Origins of the modern mind: Three stages in the evolution of culture and cognition. Cambridge, MA: Harvard University Press.

Dourish, P. (2001). Where the action is: The foundations of embodied interaction. Cambridge, MA: MIT Press. 
Dreyfus, H. (1991). Being-in-the-world: A commentary on Heidegger's Being and time, division I. Cambridge, MA: MIT Press.

Ehn, P. (1988). Work-oriented design of computer artifacts. Stockholm, Sweden: Arbetslivscentrum.

Engeström, Y. (1987). Learning by expanding: An activity-theoretical approach to developmental research. Helsinki, Finland: Orienta-Kosultit Oy.

Engeström, Y. (1999). Activity theory and individual and social transformation. In Y. Engeström, R. Miettinen \& R.-L. Punamäki (Eds.), Perspectives on activity theory. (pp. 19-38). Cambridge, UK: Cambridge University Press.

Engeström, Y. (2008). From teams to knots. Cambridge, UK: Cambridge University Press.

Floyd, C. (1992). Software development and reality construction. In C. Floyd, H. Zuellinghoven, R. Budde \& R. Keil-Slawik (Eds.), Software development and reality construction. (pp. 86-100). Berlin, Germany: Springer Verlag.

Gadamer, H.-G. (1960/1988). Truth and method. New York, NY: Crossroads.

Garfinkel, H. (1967). Studies in ethnomethodology. Englewood Cliffs, NJ: Prentice-Hall.

Garfinkel, H. (2006). Seeing sociologically: The routine grounds of social action. Boulder, CO: Paradigm Publishers.

Gee, J. P. (1992). The social mind: Language, ideology, and social practice. New York, NY: Bergin \& Garvey.

Guribye, F. (2005). Infrastructures for learning: Ethnographic inquiries into the social and technical conditions of education and training. Unpublished Dissertation, Ph.D., Department of Information Science and Media Studies, University of Bergen. Bergen, Norway.

Hegel, G. W. F. (1807/1967). Phenomenology of spirit (J. B. Baillie, Trans.). New York, NY: Harper \& Row.

Heidegger, M. (1927/1996). Being and time: A translation of Sein und Zeit (J. Stambaugh, Trans.). Albany, NY: SUNY Press.

Hollan, J., Hutchins, E., \& Kirsh, D. (2000). Distributed cognition: Toward a new foundation of human-computer interaction research. ACM Transactions on Computer-Human Interaction. 7(2), 174-196.

Husserl, E. (1936/1989). The origin of geometry (D. Carr, Trans.). In J. Derrida (Ed.), Edmund Husserl's origin of geometry: An introduction. (pp. 157180). Lincoln, NE: University of Nebraska Press.

Hutchins, E. (1996). Cognition in the wild. Cambridge, MA: MIT Press.

Johnson, D. W., \& Johnson, R. T. (1989). Cooperation and competition: Theory and research. Edina, MN: Interaction Book Company.

Jones, C., Dirckinck-Holmfeld, L., \& Lindström, B. (2006). A relational, indirect, meso-level approach to CSCL design in the next decade. International Journal of Computer-Supported Collaborative Learning. 1(1), 35-56.

Kant, I. (1787/1999). Critique of pure reason. Cambridge, UK: Cambridge University Press.

Kaptelinin, V., \& Nardi, B. A. (2006). Acting with technology: Activity theory and interaction design. Cambridge, Mass.: MIT Press. 333 p. pages.

Kershner, R., Mercer, N., Warwick, P., \& Staarman, J. K. (2010). Can the interactive whiteboard support young children's collaborative communication and thinking in classroom science activities? International Journal of Computer-Supported Collaborative Learning. 5(4). 359-383. 
Latour, B. (1992). Where are the missing masses? The sociology of a few mundane artifacts. In W. E. Bijker \& J. Law (Eds.), Shaping technology/building society. (pp. 225-227). Cambridge, MA: MIT Press.

Latour, B. (2007). Reassembling the social: An introduction to actor-networktheory. Cambridge, UK: Cambridge University Press.

Lave, J., \& Wenger, E. (1991). Situated learning: Legitimate peripheral participation. Cambridge, UK: Cambridge University Press.

Linell, P. (2001). Approaching dialogue: Talk, interaction and contexts in dialogical perspectives. New York, NY: Benjamins.

Linell, P. (2009). Rethinking language, mind, and world dialogically: Interactional and contextual theories of human sense-making. Charlotte, NC: Information Age Publishing.

Looi, C.-K., So, H.-j., Toh, Y., \& Chen, W. (2011). CSCL in classrooms: The Singapore experience of synergizing policy, practice and research. International Journal of Computer-Supported Collaborative Learning.

Marx , K. (1867). Das kapital: Kritik der politischen oekonomie (Vol. I). Hamburg, Germany: Otto Meisner.

Maturana, H. R., \& Varela, F. J. (1987). The tree of knowledge: The biological roots of human understanding. Boston, MA: Shambhala.

Mead, G. H. (1934/1962). Mind, self and society. Chicago, IL: University of Chicago Press.

Mercer, N. (2000). Words and minds. How we use language to think together: Routledge.

Nardi, B. (Ed.). (1996). Context and consciousness: Activity theory and humancomputer interaction. Cambridge, MA: MIT Press.

Plato. (340 BC/1941). The republic (F. Cornford, Trans.). London, UK: Oxford University Press.

Polanyi, M. (1966). The tacit dimension. Garden City, NY: Doubleday.

Robbins, P., \& Aydede, M. (Eds.). (2009). The Cambridge handbook of situated cognition. Cambridge, UK: Cambridge University Press.

Rogoff, B. (1995). Sociocultural activity on three planes. In B. Rogoff, J. Wertsch, P. del Rio \& A. Alvarez (Eds.), Sociocultural studies of mind. (pp. 139164). Cambridge, UK: Cambridge University Press

Sacks, H. (1962/1995). Lectures on conversation. Oxford, UK: Blackwell.

Sacks, H., Schegloff, E. A., \& Jefferson, G. (1974). A simplest systematics for the organization of turn-taking for conversation. Language. 50(4), 696-735.

Scardamalia, M., \& Bereiter, C. (1996). Computer support for knowledge-building communities. In T. Koschmann (Ed.), CSCL: Theory and practice of an emerging paradigm. (pp. 249-268). Hillsdale, NJ: Lawrence Erlbaum Associates.

Schatzki, T. R., Knorr Cetina, K., \& Savigny, E. v. (Eds.). (2001). The practice turn in contemporary theory. New York, NY: Routledge.

Schegloff, E. A. (2007). Sequence organization in interaction: A primer in conversation analysis. Cambridge, UK: Cambridge University Press.

Schön, D. A. (1983). The reflective practitioner: How professionals think in action. New York, NY: Basic Books.

Sfard, A. (2008). Thinking as communicating: Human development, the growth of discourses and mathematizing. Cambridge, UK: Cambridge University Press. 
Shannon, C., \& Weaver, W. (1949). The mathematical theory of communication. Chicago, Il: University of Illinois Press.

Stahl, G. (2002). Groupware goes to school. In J. H. J. Pino (Ed.), Groupware: Design, implementation and use: Proceedings of the 8th international workshop on groupware (CRIWG '02). (pp. 7-24). La Serena, Chile: Springer Lecture Notes in Computer Science 2440. Web: http://GerryStahl.net/cscl/papers/ch11.pdf.

Stahl, G. (2006). Group cognition: Computer support for building collaborative knowledge. Cambridge, MA: MIT Press.

Stahl, G. (2009). Studying virtual math teams. New York, NY: Springer.

Stahl, G. (2010a). Group cognition as a foundation for the new science of learning. In M. S. Khine \& I. M. Saleh (Eds.), New science of learning: Cognition, computers and collaboration in education. (pp. 23-44). New York, NY: Springer. Web: http://GerryStahl.net/pub/scienceoflearning.pdf.

Stahl, G. (2010b). Guiding group cognition in CSCL. International Journal of Computer-Supported Collaborative Learning. 5(3), 255-258.

Stahl, G. (2010c). Marx and Heidegger. Philadelphia. PA: Gerry Stahl at Lulu. 217 pages. Web: http://GerryStahl.net/elibrary/marx.

Stahl, G. (2010d). Tacit and explicit understanding. Philadelphia, PA: Gerry Stahl at Lulu. 374 + xii pages. Web: http://GerryStahl.net/elibrary/tacit.

Stahl, G., Koschmann, T., \& Suthers, D. (2006). Computer-supported collaborative learning: An historical perspective. In R. K. Sawyer (Ed.), Cambridge handbook of the learning sciences. (pp. 409-426). Cambridge, UK: Cambridge University Press. Web: http://GerryStahl.net/elibrary/global.

Suchman, L. (1987). Plans and situated actions: The problem of human-machine communication. Cambridge, UK: Cambridge University Press.

Teasley, S. D., \& Roschelle, J. (1993). Constructing a joint problem space: The computer as a tool for sharing knowledge. In S. P. Lajoie \& S. J. Derry (Eds.), Computers as cognitive tools. (pp. 229-258). Mahwah, NJ: Lawrence Erlbaum Associates, Inc.

Turing, A. M. (1937). On computable numbers, with an application to the entscheidungsproblem. Proceedings of the London Mathematical Society. 2(1), 230.

Vygotsky, L. (1930/1978). Mind in society. Cambridge, MA: Harvard University Press.

Wegerif, R. (2007). Dialogic, education and technology: Expanding the space of learning. New York, NY: Kluwer-Springer.

Wells, G. (1999). Dialogic inquiry: Towards a socio-cultural practice and theory of education. Cambridge, UK: Cambridge University Press.

Winograd, T., \& Flores, F. (1986). Understanding computers and cognition: A new foundation of design. Reading, MA: Addison-Wesley.

Wittgenstein, L. (1921/1974). Tractatus logico philosophicus. London, UK: Routledge.

Wittgenstein, L. (1953). Philosophical investigations. New York, NY: Macmillan. 